\title{
Photoplethysmographic signal processing using adaptive sum comb filter for pulse delay measurement
}

\author{
Kristjan Pilt, Kalju Meigas, Rain Ferenets and Jüri Kaik \\ Department of Biomedical Engineering, Technomedicum, Tallinn University of Technology, \\ Akadeemia tee 21, 12618 Tallinn, Estonia; \{kristjan.pilt, kalju, rafe, jyri\}@cb.ttu.ee \\ Received 28 October 2009, in revised form 19 January 2010

\begin{abstract}
Pulse transit time, which correlates with blood pressure, is measured between the electrocardiogram R-wave peak and 50\% raising front level of a photoplethysmographic (PPG) signal. Registered PPG signal bandwidth may be shared by noise and therefore the signal raising front is undetectable. Electrocardiogram reference adaptive sum comb filter was used to extract the harmonic components of the PPG signal and suppress the noises between them. Averaging effect of the filter on the PPG signal was studied and adjustments were made. The influence of the comb filtered PPG signal on the measurement of pulse transit time was analysed.
\end{abstract}

Key words: photoplethysmography, electrocardiography, pulse transit time, adaptive comb filter.

\section{INTRODUCTION}

Pulse transit time (PTT) is the time of a pulse wave to travel between two arterial sites. It has been shown that PPT is inversely proportional to systolic blood pressure [ $\left.{ }^{1}\right]$. Different methods have been used to measure the PTT, such as Doppler ultrasound, piesoelectrical pressure sensors, PPG $\left[{ }^{2,3}\right]$. The interval between the peak of the R-wave on the ECG and the raising front of the PPG signal can serve for PTT measurement $\left[{ }^{4}\right]$. In the literature this method is also called "R-wave-gated photoplethysmography" (RWPP).

ECG signals characterize the electrical activity of the heart. Electrical waves can be measured at selectively placed electrodes on the skin. Electrodes on different sides of the heart measure the activity of different parts of the heart muscle. ECG signal shape varies depending on the placement of the electrodes. In a standard solution, the ECG is measured with 10 electrodes, out of which 12 different signals are combined. To measure RWPP, three electrodes are used to 
compose one ECG signal. Electrodes should be placed so that the QRS complex with a sharp R-peak can be detected.

PPG is a non-invasive optical technique for measuring changes in blood circulation, mainly used for monitoring blood perfusion in skin. The optical radiation from the light source is emitted to the skin, where the blood volume and its changes are measured. The incident light, which is often red or infrared, is absorbed, reflected and scattered in the tissue and blood. Only a small fraction of light intensity changes are received by the photodetector. Changes in the intensity of the received light are related to the blood flow in the underlying tissue $\left[{ }^{5}\right]$.

There are two main ways to measure a PPG signal: the reflection and the transmission mode. In the reflection mode, a photodetector is placed adjacent to the light source and directed toward skin. Only a small fraction of the reflected and scattered light is received by the photodetector. The photodetector measures the reflected and scattered light intensity from the skin surface. In the transmission mode, the photodetector and the light source are placed on opposite sides of the measured volume. The photodetector measures the transmitted light intensity.

Measured PPG signals can be divided into two components: the DC and the AC component. The DC component of the signal varies slowly and reflects variations in the total blood volume of the examined tissue. The AC component is synchronous with the heart rate and depends on the changes in the pulsatile pressure and pulsatile blood volume. The amplitude of the AC component can be over ten times smaller than that of the DC component.

PPG signal shape is slowly varying and its starting point is difficult to determine. Raising front is the sharpest part of the PPG signal where the derivative is maximal. According to previous research, the pulse delay (PD) that is measured similarly to RWPP is suggested to be measured between 50\% of the PPG signal raising front and ECG signal R-peak $\left[{ }^{2}\right]$. In this article we denote this delay as PD50.

In 24-hour PPG signal monitoring devices $\left[{ }^{6}\right]$, the PPG signal can be with low signal-to-noise ratio (SNR) because of poor perfusion state and different noises (e.g., power line interference) and motion artifacts. Different methods have been applied to remove the unwanted noises. By using a band-pass filter it is possible to remove the DC component and higher frequency noises, including power line interference. Still this filtering does not remove noises caused by the PPG sensor movement, which are in the band pass region. Recent research has also shown that noises caused by motion can be successfully removed by using additional acceleration sensors and an adaptive filter $\left.{ }^{7,8}\right]$. The first input of the adaptive filter is the PPG signal with noise and the second input is unwanted noise from acceleration sensors. Motion-caused noises are removed by using the LMS algorithm.

Comb filter is an alternative method to remove noises, which are sharing the same bandwidth with the PPG signal. The AC component of the PPG signal can be described by its harmonic components. Fundamental harmonic is related to the heart pulsation frequency. All the other components are at the frequency multiples of the fundamental frequency. By using a comb filter, it extracts the 
PPG signal harmonic components and suppresses the noises between them. As the PPG signal periods are not of constant length, the comb filter frequency response needs to be calculated for every period. ECG signal can be used as the reference to determine the fundamental frequency of a comb filter. This article proposes an ECG-referenced comb filter design for PPG signals and analyses its influence on the measurement of PD50.

\section{METHODS}

\subsection{Sum comb filter design for PPG signals}

In this article it is assumed that all signals are discrete, if it is not otherwise stated. The discrete signal, $x[k]$, consists of periodically taken samples of the analogue signal, $x(t)$, where $k$ is integer and refers to sample number in the sequence and $t$ is time in seconds.

Comb filter frequency response consists of a series of regularly spaced spikes. A sum FIR comb filter is expressed as $\left[{ }^{9}\right]$

$$
y[k]=\frac{x[k]+x[k-D]}{2},
$$

where $x[k]$ is the filter input signal, $y[k]$ is the filter output signal and $D$ is an integer. Depending on the value of $D$, the comb filter sums up two samples from the signal and calculates the average; $D$ also determines the comb filter frequency response. On the $z$-plane $\left[{ }^{10}\right]$ a comb filter is formed with the number of $D$ poles at the origin and the number of $D$ zeros, $z$, evenly spaced unit circle at $\left[{ }^{9}\right]$ :

$$
z=\exp \left[\frac{j(2 l+1) \pi}{D}\right]
$$

where $l$ is an integer $(l=0,1, \ldots, D-1)$. By substituting $z=e^{j \omega T}$ in Eq. (2), the comb filter frequency response can be expressed as $\left[{ }^{9}\right]$ :

$$
H(j \omega T)=\exp \left(-j \frac{D \omega T}{2}\right) \cos \left(\frac{D \omega T}{2}\right),
$$

where $\omega$ is the normalized frequency, $T$ is the sampling interval and $H$ is the frequency response. Figure 1a shows the frequency response for the sum comb filter with $D=10$ zeros and Fig. $1 \mathrm{~b}$ demonstrates the respective $z$-plane plot. As seen from the frequency response plot, this filter does not remove the DC component because of the lowest lobe centered to zero frequency. The filter frequency response exhibits peaks at multiples of the fundamental frequency $f_{1}$ :

$$
f_{1}=\frac{f_{\mathrm{s}}}{D}
$$

where $f_{\mathrm{s}}$ is the sample frequency. 
(a)

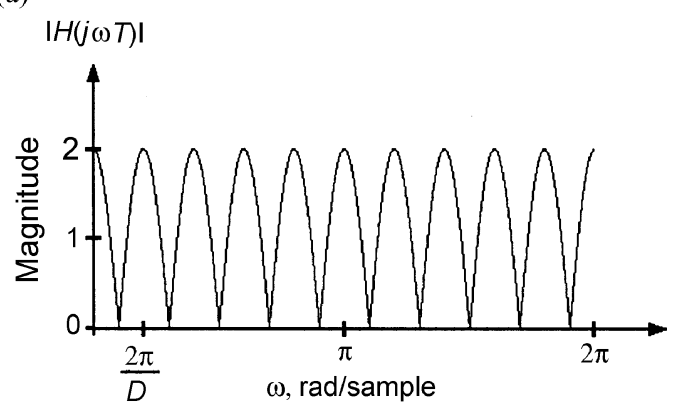

(b)

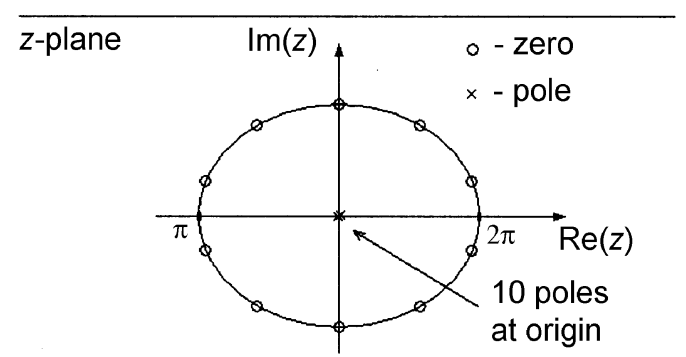

Fig. 1. (a) Comb filter magnitude response with $D=10$ zeros; (b) respective zeroes and poles plot on the z-plane.

To select $D$, it is required that the fundamental frequency of the comb filter matches the fundamental frequency of the PPG signal. In this case $D$ should be equal to the length of the PPG signal period. As a result, according to Eq. (1), the comb filter averages sample by sample two consecutive PPG signal periods. In practice, the biosignals, e.g. PPG and ECG, which are related to the heart, are recurring but not periodic. Because two consecutive recurrences are of different length, they should be equalized during the comb filter averaging process.

The process of equalization can be explained as follows (Fig. 2). Let the two consecutive recurrences $R_{1}(m=1, \ldots, M)$ and $R_{2}(k=1, \ldots, K)$ of the signal have different lengths $M$ and $K$, respectively, $(K \neq M)$, where $m$ and $k$ are sample numbers within recurrences. The equalization is based on the $R_{2}$ recurrence length currently being processed. In the previous recurrence $R_{1}$, each sample number responds to the sample number of the recurrence $R_{2}$ through the following relation:

$$
m=\frac{k K}{M}
$$

As the sample numbers must be integers, $m$ is rounded to the closest integer. Starting points for each PPG signal recurrence are determined from synchronously measured ECG signals. Each QRS complex marks the starting point of the next recurrence. 


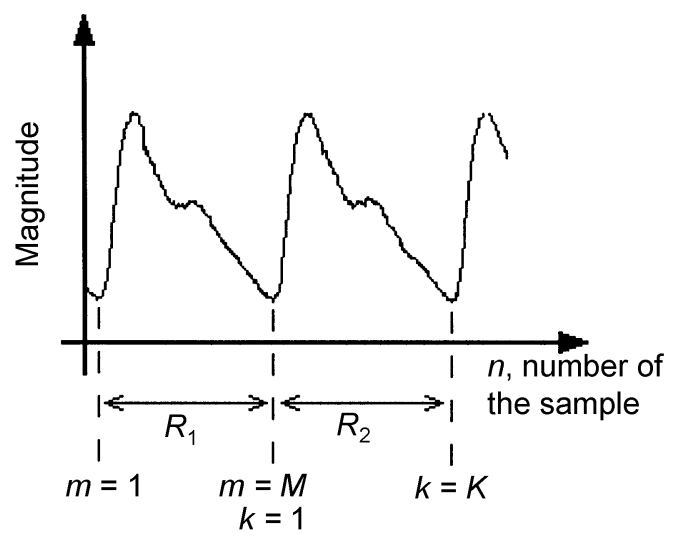

Fig. 2. Two consecutive signal recurrences $R_{1}$ and $R_{2}$ with different durations $M$ and $K$, respectively.

Samples average calculations by the comb filter can be expanded over a larger number of signal recurrences. It allows for higher noise attenuation to be obtained. Assume that in a general calculation $(r-1)$ recurrences are used with $r \geq 2$, where $r$ is integer number of recurrences. Then the modified comb filter is given by the equation

$$
y[k]=x[k-D]+x[k-2 D]+\ldots+x[k-(r-1) D] .
$$

On the $z$-plane, the filter zeroes, $z$, are located as follows $\left[{ }^{9}\right]$ :

$$
z=\exp \left(j \frac{2 m \pi}{D r}\right), \quad m=0,1,2, \ldots,(D r-1)
$$

and the cancelling poles, $p$, are as follows $\left[{ }^{9}\right]$ :

$$
p=\exp \left(j \frac{2 n \pi}{D}\right), \quad n=0,1,2, \ldots,(D-1)
$$

A pole-zero plot, drawn for $D=10$ and $r=4$, is shown in Fig. 3b. The filter pass-band centres are at frequencies where the poles and zeroes are cancelling each other. Similarly to Eq. (3), the frequency response is given by $\left.{ }^{9}\right]$

$$
H(j \omega T)=\exp \left[\frac{-j(D r-D) \omega T}{2}\right] \frac{\sin \left(\frac{D r \omega T}{2}\right)}{\sin \left(\frac{D \omega T}{2}\right)}
$$

as plotted in Fig. 3a. 
(a)

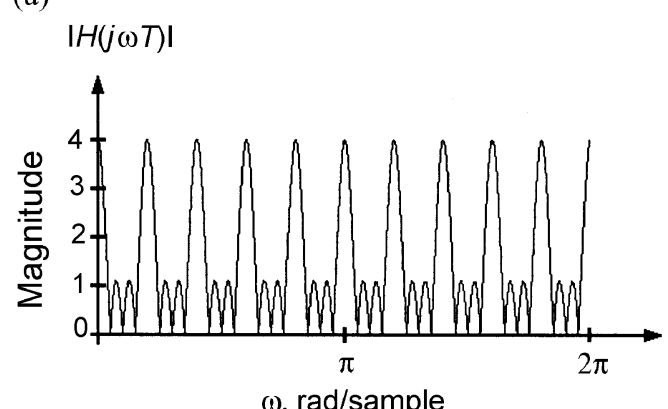

(b)

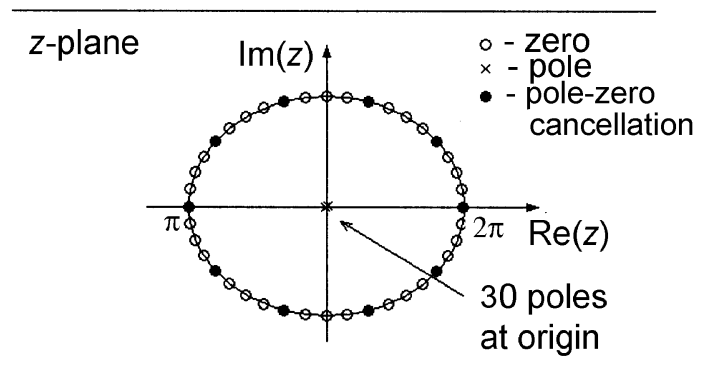

Fig. 3. (a) Response of the modified comb filter magnitude with $D=10$ and $r=4$; (b) plot of respective zeroes and poles on the $z$-plane.

By enlarging the number of recurrences, $r$, in the filter output calculation it is possible to minimize the noise between the main lobes of the filter more effectively. Table 1 shows the relationship between the number of recurrences used in the filter output calculation and the attenuation of the first side lobe of the stop-band. The first side lobe attenuations are calculated by using Eq. (9), where $D$ is kept constant and $r$ is changed according to Table 1 . It is clear from Table 1 that using more than four or five recurrences will not lead to a considerable advantage, as with ten recurrences the attenuation is only $13.1 \mathrm{~dB}$.

Table 1. Relationship between the first side lobe attenuation of the comb filter stop-band and the number of filter averaged recurrences $r$

\begin{tabular}{r|c}
\hline$r$ & Attenuation, dB \\
\hline 2 & 0.0 \\
3 & 9.5 \\
4 & 11.4 \\
5 & 12.1 \\
6 & 12.6 \\
10 & 13.1
\end{tabular}




\subsection{Comb filter adjustment}

Averaging behaviour of a comb filter causes a decrease in signal shape differences between the beats. From Eqs. (1) and (6) it follows that every recurrence has the same weight in the filter output calculation. The filter weights can be adjusted so that the filter uses less information from a larger number of passed recurrences $\left[{ }^{11}\right]$. The sum comb filter, described by Eq. (6), can be rewritten as

$$
y[k]=\frac{x[n]+\sum_{n=2}^{r} a_{n-1} \cdot x[k-(n-1) D]}{1+\sum_{n=2}^{r} a_{n-1}},
$$

where $a_{n}$ is the weight of the recurrence. By using discrete Fourier transform on Eq. (10), the corresponding frequency response, similarly to Eq. (9), is obtained:

$$
H(j \omega T)=\frac{1+\sum_{n=2}^{r} a_{n-1} e^{-(n-1) j \omega D}}{1+\sum_{n=2}^{r} a_{n-1}} .
$$

Each weight, $a_{n}$, describes the amount of information, which is taken from the previous recurrence for the filter output calculation. In Eq. (6), all the weights are equal to one.

The changes of weights cause the changes in the filter frequency response shape. Here the comb filter weights are adjusted according to the following criteria: a) all weights should be as small as possible and $a_{1}>a_{2}>\ldots>a_{r-1}$; at the same time the adjusted filter frequency response should be as close to the filter frequency response as possible, as described by Eq. (9);

b) the whole stop-band magnitude of the adjusted filter should be at least as low as the first side lobe magnitude of the non-adjusted filter.

Filter weights $a_{n} \quad(0<n<r$, where $n$ and $r$ are integers $)$ are calculated numerically. The frequency response for the adjusted filter is calculated from Eq. (11) for all weights by changing $a_{n}$ from 0 to 1 with step $s$. The magnitude of the adjusted filter in the place of the first side lobe maximum of the nonadjusted filter and the stop-band maximum are calculated and separated into square matrices $\mathbf{L}$ and $\mathbf{M}$, respectively. The dimensions of $\mathbf{M}$ and $\mathbf{L}$ equal to $r-1$, if $r>2$. In the case $r=3, \mathbf{M}$ and $\mathbf{L}$ are $1 / s \times 1 / s$ matrices.

First, all the values in the $\mathbf{M}$ matrix, exceeding the allowed maximum, are eliminated. In the next step, the matrix is scanned through. Scanning is explained here for the case $r=4$, which means that $\mathbf{M}$ is a $3 \mathrm{D}$ matrix.

Matrix $\mathbf{M}$ elements are $m_{i j k}$. It must be noted that $i s=a_{1}, j s=a_{2}$ and $k s=a_{3}$. Scanning starts when $i=j=k=0$. The value of $k$ is changed until the end of the matrix row. In the next step $i=0, j=1$ and again the $k$ value is 
changed until the end of the matrix row. The previously explained scanning sequence is processed until the first existing matrix value is found, which was not eliminated before, and it should correspond to the condition $i>j>k$. Weights for the adjusted filter are found and scanning is finished if the $\mathbf{L}$ matrix value, in place of $i, j$ and $k$, is lower than the allowed maximum. Otherwise scanning is continued until the weights are found.

Numerical calculations of the weights were made in MATLAB. Weights were changed from 0 to 1 with a step of $s=0.04$. Table 2 shows weights for adjusted filters. The plot for respective frequency responses for adjusted filters is given in Fig. 4.

Table 2. Calculated weights for the adjusted comb filter

\begin{tabular}{c|c|c|c|c}
\hline$r$ & $a_{1}$ & $a_{2}$ & $a_{3}$ & $a_{4}$ \\
\hline 3 & 0.64 & 0.20 & - & - \\
4 & 0.72 & 0.44 & 0.12 & - \\
5 & 0.68 & 0.60 & 0.36 & 0.12
\end{tabular}

(a)

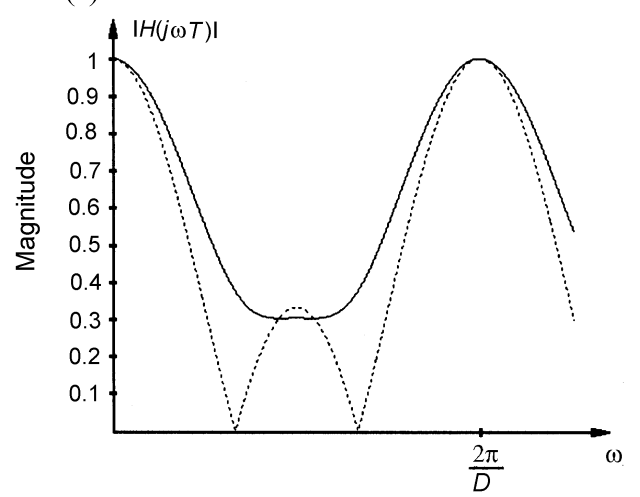

(b)

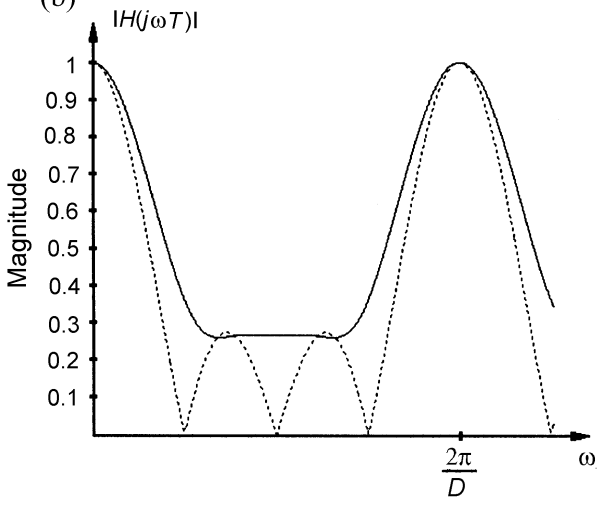

(c)

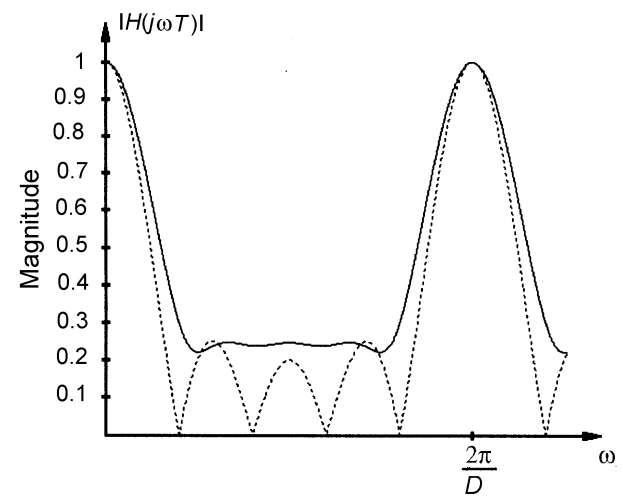

Fig. 4. Adjusted (solid line) and non-adjusted (dashed line) sum comb filter frequency responses in the case $D=8$ : (a) frequency response in case $r=3$; (b) $r=4$; (c) $r=5$. 


\subsection{Influence of the comb filter on the pulse delay measurement}

As explained above, PD50 is measured between the ECG signal R-peak and the $50 \%$ PPG signal raising front level. As the PPG signal has slow behaviour, it is difficult to determine the starting point of the recurrence. In previous studies the starting point of the PPG signal recurrence was detected from its maximum or minimum point, but it is not sufficiently accurate $\left[{ }^{2}\right]$. The raising front is the fastest changing part in the PPG signal. In case the calculated 50\% level is between two samples, it is possible to interpolate the signal as the front rises linearly. It allows for a more precise determination of PD50. The 50\% level is calculated for each recurrence separately. Within one recurrence, the maximum and minimum points of the PPG signal are detected and the 50\% level is calculated.

Comb filter output can also be taken also as a product of the moving window average $\left[{ }^{12}\right]$. Therefore the output signal is delayed for half of the number of periods used in the filter calculation.

Let the comb filter output be calculated from two consecutive recurrences. It is expected that PD50 is an average of the two consecutive recurrences PD50. The PD50 mean value is calculated as

$$
\mathrm{PD}_{2}(n)=\frac{\operatorname{PD} 50(n-1)+\operatorname{PD} 50(n)}{2},
$$

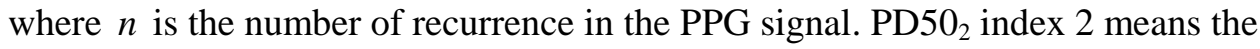
number of recurrences used in the filter output calculation. A generalization of Eq. (12) can be written as:

$$
\operatorname{PD50}_{r}(n)=\frac{1}{r} \sum_{m=n-r+1}^{n} \operatorname{PD} 50(m) .
$$

Equation (13) can be interpreted as the moving average window method with the window length $r$. The output of the moving average window is delayed regarding to input by half the window length, which is similar to the filter output calculation. It means that the PD50, measured from the comb filtered signal, is an average over $r$ recurrences and delayed by half of the $r$ recurrences.

In addition to the procedure described, test signals were generated in MATLAB to analyse the influence of the comb filter on the PD50 measurement. The first input of the signal generator is the unit impulse train, related to the ECG signal (Fig. 5c). Each unit impulse marks the ECG signal R-peak.

Impulses appeared at constant frequency $1 \mathrm{~Hz}$. The second generator input is PD50 that determines the PPG signal raising front delay from the R-peak for each generated recurrence (Fig. 5b). In the middle of the generated signal, the PD50 varies between 0.25 and $0.35 \mathrm{~s}$. One period from a raw PPG signal was taken as a template. The PPG signal template was stretched and compressed through rescaling it for every generated recurrence to achieve the given PD50 (Fig. 5a). 
(a)

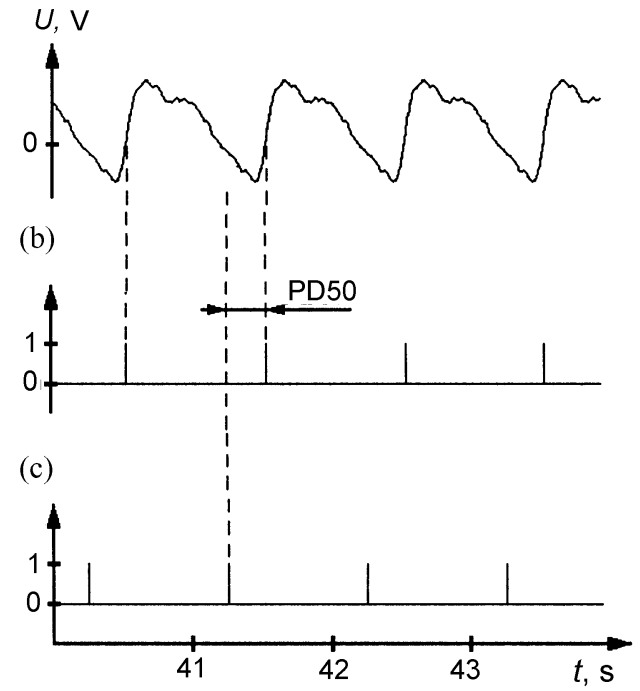

Fig. 5. (a) Part of the generated signal; (b) impulses, which are marking the detection of PPG signal raising front $50 \%$ level; (c) first PPG signal generator input signal (impulse train, which is related to the ECG signal R-peak).

In the next step, the PD50 was measured by using a raw generated signal and PPG signals filtered with comb filters. Two and six recurrence averaging comb filters were used. Results are shown in Fig. 6. It can be seen that the PD50, measured by using the raw generated PPG signal, differs from that of the filtered

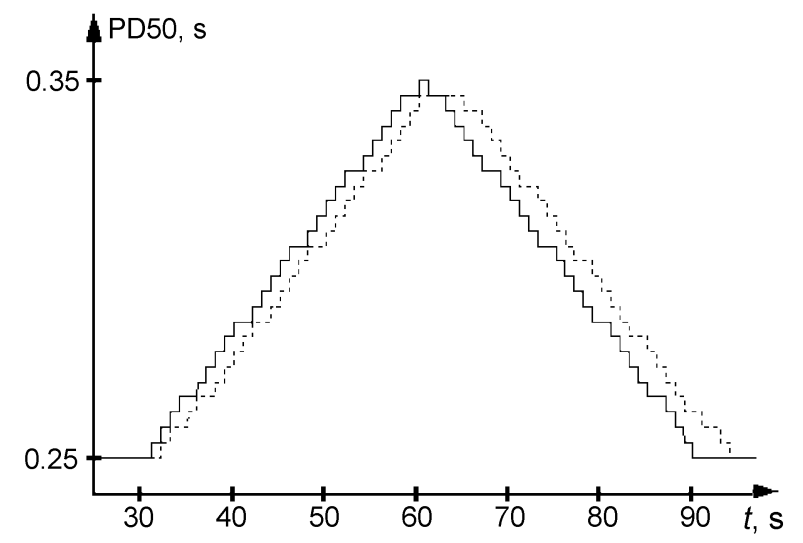

Fig. 6. Measured PD50 values while using raw generated PPG signal (solid line); generated signal, which is preprocessed with six recurrences averaging comb filter (dotted line); PD50 values varied linearly over the given range. 


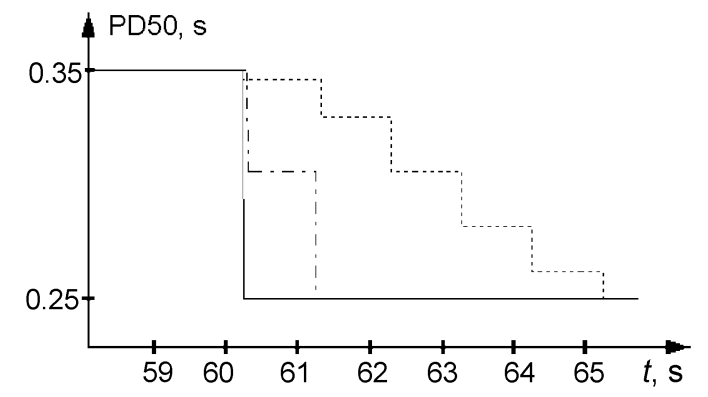

Fig. 7. Measured PD50 values while using raw generated PPG signal (solid line); generated PPG signal, which is preprocessed with two recurrences averaging comb filter (dash dotted line); generated PPG signal, which is preprocessed with six recurrences averaging comb filter (dotted line); PD50 value was changed in the middle of generated signal from 0.35 to $0.25 \mathrm{~s}$.

signals. As discussed above, the comb filtered signal PD50 is shifted from the raw signal PD50. To illustrate, how a comb filter influences fast changes in the PD50, a test signal was generated. In the middle of the generated PPG signal, the PD50 changed sharply from 0.35 to $0.25 \mathrm{~s}$. Figure 7 shows the results of the PD50 measurement in the case of a raw PPG signal and the comb filtered signals using two and six recurrences for the filter output calculation.

In the case of a sharp PD50 change, the reaction time for the adaptive comb filter with six recurrences averaging is longer than for the adaptive comb filter with recurrences averaging, as it was discussed above. For fast changes in registered signals, similar behaviours are expected.

\section{EXPERIMENTS AND RESULTS}

Experiments concentrated on the analysis of the adaptive comb filter with real signals. The raw PPG and ECG signals were registered from forehead by using a laboratory built circuit. Signals were recorded synchronously using the LabView environment and National Instruments DAQCard 6036. The analogue-to-digital conversion was made with $250 \mathrm{~Hz}$ sampling rate and 16-bit resolution. Digital signal processing was carried out in MATLAB. To show how filters act at low SNR signals the subject was doing squat downs during the recording process.

Firstly, the PPG signal was filtered with the band-pass filter composed of a separated high- and a low-pass filter. FIR high-pass and low-pass filters, designed by using the rectangular window method, have the cut-off frequencies at 0.3 and $30 \mathrm{~Hz}$ with orders of 850 and 200, respectively. After band-pass filtering, the signals were processed with the ECG referenced adjusted adaptive comb filter, which uses four recurrences for the output calculation.

The results are shown in Fig. 8. The raw PPG signal shows a noticeably high noise rate because of squat downs (Fig. 8a). After high- and low-pass filtering, the signal DC component and high frequency noises are eliminated (Fig. 8b). Still visually it is almost impossible to detect a pulsatile PPG signal. The 
respective signal segment spectrum is shown in Fig. 8d. Higher magnitude peaks appear at frequencies 1,2 and around $4 \mathrm{~Hz}$.

The signal after the adaptive comb filter is given in Fig. $8 \mathrm{c}$. The pulsatile shape of the PPG signal is visible and detectable. The respective signal segment spectrum is shown in Fig. 8e. The higher magnitude peak around $1 \mathrm{~Hz}$ appears

(a)

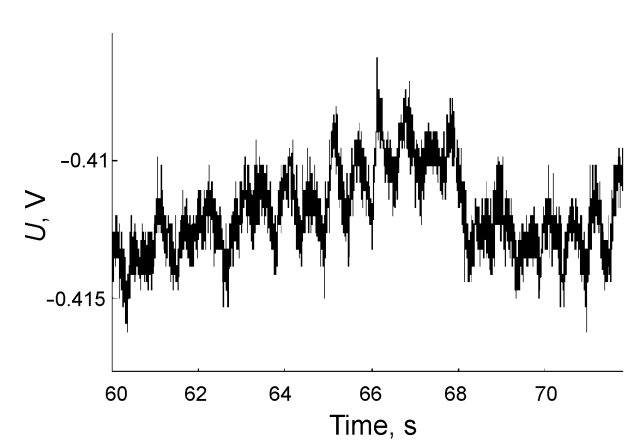

(c)

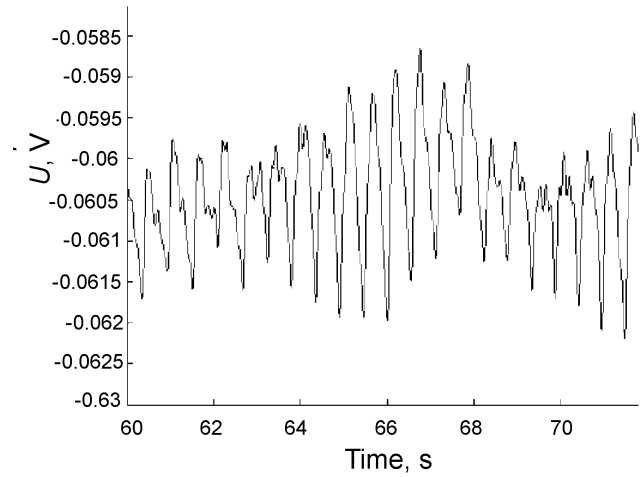

(e) (b)

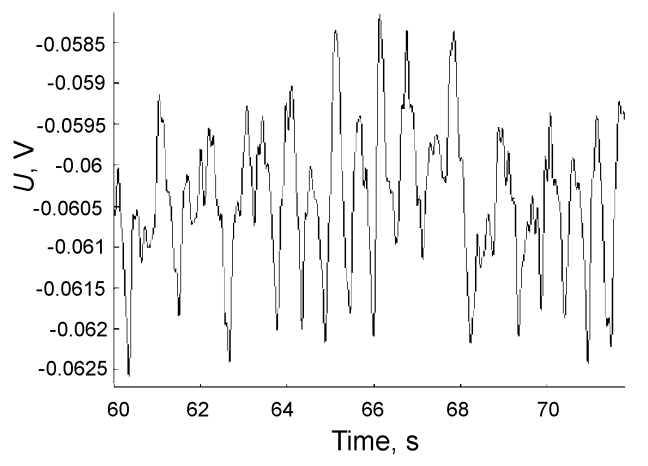

(d)

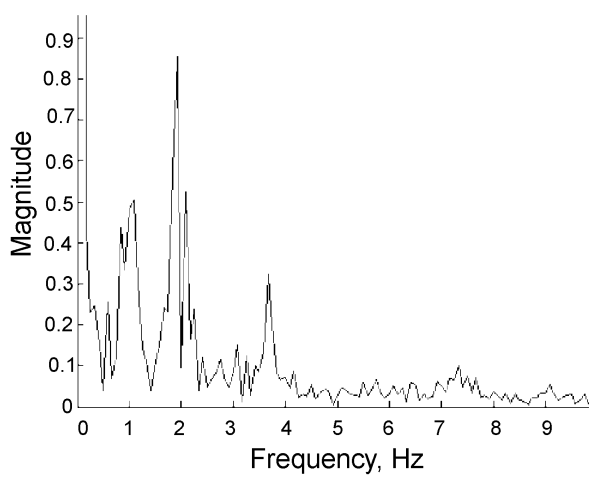

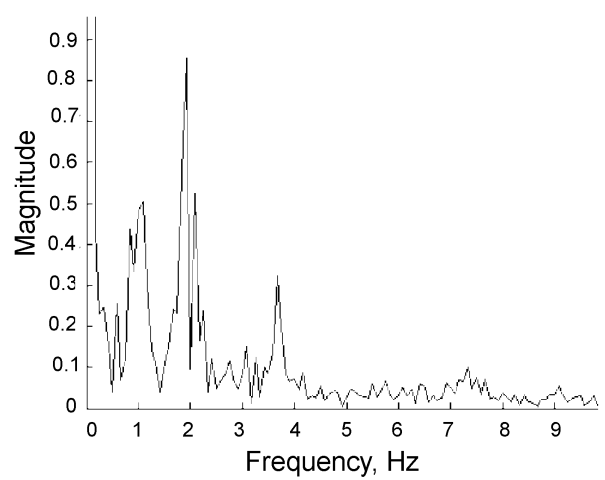

Fig. 8. (a) Raw PPG signal recorded from the forehead; (b) PPG signal after high- and low-pass filters; (c) PPG signal after adaptive comb filter; (d) signal spectrum after high- and low-pass filter; (e) signal spectrum after adaptive comb filter. 
reduced, which might correspond to a noise, caused by motion. Also, at higher frequencies, between the PPG signal harmonics, noise reduction is visible.

To show influence of the comb filter on the PD50 measurement, the PPG and ECG signals were recorded while the subject was carrying out the Valsalva maneuver $\left[{ }^{13}\right]$. The PPG signal in this experiment was registered from forehead. During the Valsalva maneuver, the subject's blood pressure and heart rate changed. Recorded signals were with high SNR, as the subject was sitting during the experiment. Comparison was made between two PD50 measurements. The first PD50 measurement was made by using raw PPG signal and the second one by using the comb filtered PPG signal.

After the recording session, the PPG and ECG signals were processed offline. The PPG signal was filtered with high- and low-pass filters as described in the previous experiment above. In the next step, the PD50 was measured between the ECG signal R peaks and the PPG signal raising fronts. Subsequently the PPG signal was filtered with two comb filters, which used two and four recurrences for the output calculation. Both of the filtered PPG signals were used to measure PD50.

The results are shown in Fig. 9. Typical heart rate rise at the Valsalva maneuver can be seen at $105 \mathrm{~s}$ in Fig. 9d. Figures 9a-c show the calculated inverse values of PD50, by using different preprocessed PPG signals and the synchronous ECG signal. Inverse PD50 should be taken as relative blood pressure. It is not equal to certain blood pressure estimations.

Figure 9c shows that at the beginning of the Valsalva maneuver (95 s), the typical blood pressure changes, which is not so clearly seen in other signals. Also, the inverse PD50 shift is visible between the signals in Figs. 9b and 4c. The PD50 that is determined from the four recurrence averaging comb filter has a smoother shape than the other two signals, caused by the averaging property of the comb filter.

The small fluctuations in the signal in Fig. 9a may be caused by imprecise $50 \%$ raising front detection or directly related to blood pressure changes. On the one hand, by using a large number of recurrences for averaging the signal, more noise is suppressed. The detection of the PPG signal front is more precise. On the other hand, because of averaging the small changes in the signal may be lost. It is necessary to find a balance for the number of recurrences.

In our experiments we compared adjusted and non-adjusted comb filters that use a different number of recurrences $r$. The PPG signal was generated in MATLAB. The PPG signal was generated by using a one-period length template. In addition, a reference signal was generated, composed of unit impulses, whereas each impulse marked the beginning of the PPG signal period.

Generated PPG signal heart rate frequency was varied from 1 to $2 \mathrm{~Hz}$ during $24 \mathrm{~s}$. The noise was generated by using the MATLAB random number generator and added to the PPG signal. Four PPG signals with different SNR were generated. Generated signals were filtered with three adjusted and three non-adjusted adaptive comb filters. Adjusted filters were using weights given in Table 2. After filtering, the signal SNR was measured and noise attenuation was calculated. 
(a)

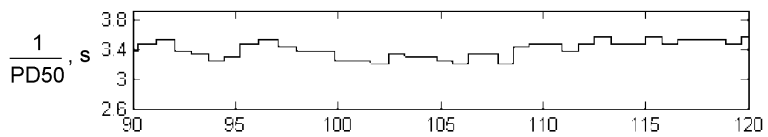

(b)

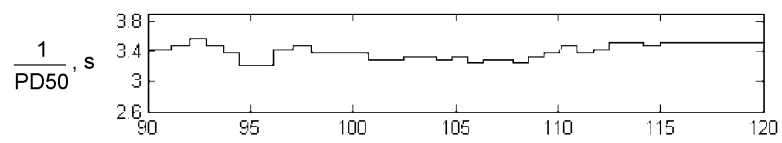

(c)

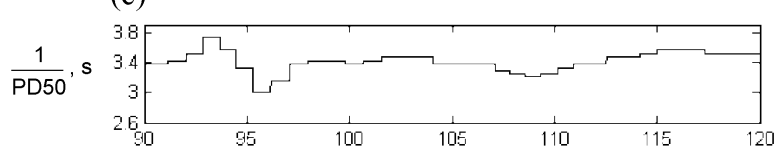

(d)

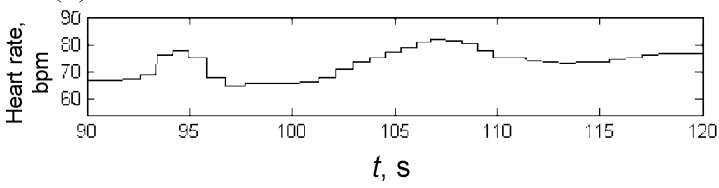

Fig. 9. Signals are starting from the beginning of the Valsalva maneuver: (a) calculated inverse value of PD50 by using ECG and only a high-pass filtered PPG signal; (b) calculated inverse value of PD50 by using ECG and comb filtered PPG signal, where comb filter used two recurrences for averaging; (c) calculated inverse value of PD50 by using ECG and the comb filtered PPG signal, where the comb filter used four recurrences for averaging; (d) heart rate.

Table 3 shows the results and Fig. 10 illustrates the use of information. The aim of the comb filter adjustment was to decrease the effect of the filter on the signal shape averaging by using less information from previous recurrences. The amount of information that filters are using from previous recurrences is given in Table 2; $100 \%$ corresponds to the situation when samples of one recurrence are involved to the filter output calculation with weight 1 . It can be seen that the amount of information is reduced twice. At the same time, less information is taken from past recurrences.

Table 3. Non-adjusted and adjusted comb filter noise attenuation and use of information for output calculation

\begin{tabular}{c|r|r|r}
\hline$r$ & \multicolumn{1}{|c|}{3} & 4 & 5 \\
\hline \multicolumn{4}{c}{ Adjusted comb filter } \\
Amount of information, \% & 184 & 228 & 276 \\
Noise attenuation, dB & 18 & 24 & 32
\end{tabular}

Non-adjusted comb filter

Amount of information, \% $300 \quad 400 \quad 500$

$\begin{array}{lrrr}\text { Noise attenuation, dB } & 24 & 32 & 39\end{array}$




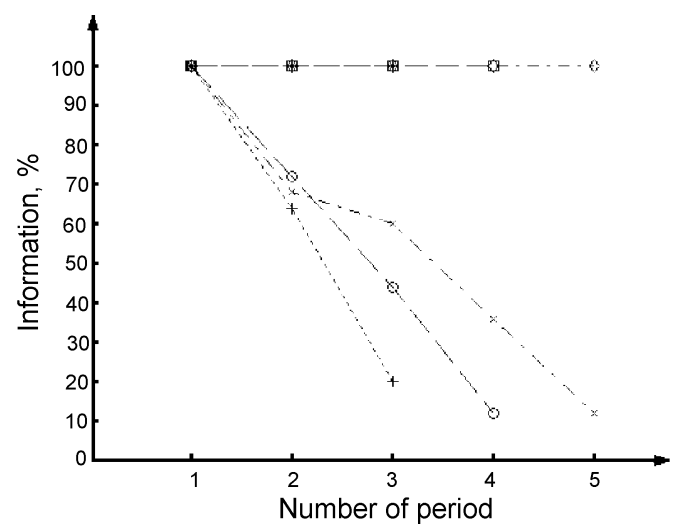

Fig. 10. Amount of information that is used for adjusted and non-adjusted comb filter output calculation; dotted line with "+": adjusted comb filter uses 3 recurrences; dashed line with "o": adjusted comb filter uses 4 recurrences; dash dotted line with "x": adjusted comb filter uses 5 recurrences.

The drawback of the adjusted filter is a decrease in noise attenuation. For every filter, the average SNR was calculated. It can be seen in Table 3 that the noise attenuation of the adjusted filters is about $7 \mathrm{~dB}$ better than of the nonadjusted filters by using the same number of recurrences for filter output calculation. It should be pointed out that noise attenuation is equal for the adjusted filter with $r$ and the non-adjusted filter with $r-1$.

\section{CONCLUSIONS}

An ECG reference adaptive comb filter has been proposed to filter out the noises that share the same bandwidth with the signal to measure the PD50. The comb filter was customized for non-periodic biosignals such as the PPG signal by equalizing the lengths of consecutive recurrences. The filter averages the signal over determined previous recurrences. Enlarging the averaging over the number of periods enables the noise attenuation to be improved. Still, it was found that using more than four or five recurrences for averaging do not give significant advantages.

The adaptive comb filter decreases differences between the beats because it calculates the average over the recurrences. Adaptive sum comb filter adjustment was performed numerically to minimize the influence of past recurrences on an ongoing processed recurrence. At the same time, the frequency response properties of the filter were kept as similar as possible to those of the nonadjusted filter. The adjustment method was explained and new weight values were calculated.

Adjusted and non-adjusted comb filter noise attenuations were compared by generating a noisy PPG signal. The adjusted filter was found to have lower noise 
attenuation than a non-adjusted filter by using the same number of recurrences. By expanding the calculation of the non-adjusted filter output over one more recurrence, in contrast to the non-adjusted filter, the noise attenuations were equal. At the same time, the adjusted filter used almost twice less information from previous recurrences than the non-adjusted filter did.

Filtered PPG and ECG signals were used to measure the PD50. The influence of the adaptive comb filter on the PD50 was analysed. The comb filter eliminates noises that share the same band width with the PPG signal and the raising fronts are detectable. The PPG signal as well as the PD50 measurement is affected by the comb filter averaging mechanism. Averaging and a PD50 shift were analysed with test signals as well as with recorded signals from the subject by the Valsalva maneuver. The averaging effect of the comb filter should be taken into account by PD50 measurements.

\section{ACKNOWLEDGEMENTS}

This study was supported by the Estonian Science Foundation (grant No. 7506), by the Estonian targeted financing project SF0140027s07, and by the European Union through the European Regional Development Fund.

\section{REFERENCES}

1. Lass, J., Meigas, K., Karai, D., Kattai, R., Kaik, J. and Rosmann, M. Continuous blood pressure monitoring during exercise using pulse wave transit time measurement. In Proc. 26th Annual International Conference of the IEEE Eng. Med. Biol. Sci. San Francisco, 2004, 2239-2242.

2. Lass, J., Meigas, K., Kattai, R., Karai, D., Kaik, J. and Rosmann, M. Optical and electrical methods for pulse wave transit time measurement and its correlation with arterial blood pressure. Proc. Estonian Acad. Sci. Eng., 2004, 10, 123-136.

3. Asmar, R., Benetos, A., Topouchian, J., Laurent, P., Pannier, B., Brisac, A. M., Target, R. and Levy, B. I. Assessment of arterial distensibility by automatic pulse wave velocity measurement. Validation and clinical application studies. Hypertension, 1995, 26, 485-490.

4. Naschitz, J. E., Bezobchuk, D., Mussafia-Priselac, R., Sundick, S., Dreyfuss, D., Khorshidi, I., Karidis, A., Manor, H., Nagar, M. et al. Pulse transit time by R-wave-gated infrared photoplethysmography: Review of the literature and personal experience. J. Clin. Monit. Comput., 2005, 18, 333-342.

5. Kamal, A., Harness, J., Irving, G. and Mearns, A. Skin photoplethysmography - a review. Comput. Methods Progr. Biomed., 1989, 28, 257-269.

6. Pilt, K., Meigas, K., Lass, J., Rosmann, M. and Kaik, J. Analogue step-by-step DC component eliminator for 24-hour PPG signal monitoring. In Proc. IEEE Eng. Med. Biol. Soc. Conference. Lion, 2007, 1006-1009.

7. Wood, L. B. and Asada, H. Low variance adaptive filter for cancelling motion artifact in wearable photoplethysmogram sensor signals. In Proc. IEEE Eng. Med. Biol. Soc. Conference, 2007, 652-655.

8. Comtois, G., Mendelson, Y. and Ramuka, P. A comparative evaluation of adaptive noise cancellation algorithms for minimizing motion artifacts in a forehead mounted wearable pulse oximeter. In Proc. IEEE Eng. Med. Biol. Soc. Conference, 2007, 1528-1531.

9. Cunningham, E. P. Digital Filtering: An Introduction. J. Wiley, New York, 1995. 
10. Oppenheim, A. V., Schafer, R. W. and Buck, J. R. Discrete-time Signal Processing, 2nd Ed. Prentice Hall, 1999.

11. Pilt, K., Meigas, K., Ferenets, R. and Kaik, J. Adjustment of adaptive sum comb filter for PPG signals. In Proc. IEEE Eng. Med. Biol. Soc. Conference. Minneapolis, 2009, vol. 1, 5693 5696.

12. Pilt, K., Meigas, K., Karai, D. and Kaik, J. PPG signal processing for pulse delay computing by using adaptive comb filter. IFMBE Proc., 2009, 25, 1653-1656.

13. Luster, E. A., Baumgartner, N., Adams, W. C. and Convertino, V. A. Effects of hypovolemia and posture on responses to the Valsalva maneuver. Aviat. Space Environ. Med., 1996, 67, 308-313.

\title{
Fotopletüsmograafilise signaali töötlus pulsi viiteaja mõõtmisel adaptiivse kammfiltriga
}

\author{
Kristjan Pilt, Kalju Meigas, Rain Ferenets ja Jüri Kaik
}

Ajalist viidet elektrokardiograafilise (EKG) signaali R-piigi ja fotopletüsmograafilise (PPG) signaali tõusva frondi vahel nimetatakse pulsi viiteajaks. Eelnevates uurimustes on täheldatud selle korreleeruvust vererõhuga. Liikuval inimesel registreeritud PPG-signaal võib olla mõjutatud liikumisest tingitud müradest. Antud töös töötati välja adaptiivne kammfilter mürade filtrimiseks, mis kasutab EKG-signaali referentsina, ja analüüsiti selle filtri mõju PPG-signaalile ning pulsilaine viiteajale.

Töös realiseeritud adaptiivse kammfiltri väljund arvutatakse korduvate signaalilõikude keskmistamise teel. EKG-signaali R-piigid tähistavad iga PPGsignaali korduse algust. Iga filtreeritava korduse jaoks interpoleeritakse eelnevad kordused sellega võrdseks. Väljundi arvutamisel võetakse igast perioodist vastava järjekorranumbriga hetkväärtus ja need keskmistatakse.

Suurendades keskmistatud korduste arvu, on võimalik saavutada suurem signaal/müra-suhe, kuid väikesed muutused signaalis võivad seetõttu ära kaduda. Selle vältimiseks kohandati kammfiltrit nii, et keskmise arvutamisel kaasatakse hetkväärtusi möödunud kordustest väiksema kaaluga.

Filtrit testiti genereeritud PPG-signaaliga, millele oli lisatud juhuslik müra. Tuginedes tehtud eksperimentidele, kasutas kohandatud filter eelnevatest perioodidest kaks korda vähem infot väljundi arvutamiseks kui kohandamata filter. Kohandatud kammfilter surus mürasid maha $7 \mathrm{~dB}$ vähem kui kohandamata filter sama korduste arvu juures.

Testimise tulemused kinnitasid, et kammfiltril on keskmistav efekt ka pulsilaine viiteaja arvutamisel. Tehtud katsetest selgus, et pulsilaine viiteaeg on nihutatud poole korduste arvu võrra. Pulsilaine viiteaja muutuse puhul rohkem kordusi kasutav filter reageerib aeglasemalt kui vähem kordusi kasutav filter.

Katsed reaalsete signaalidega näitasid, et kammfiltriga on võimalik eemaldada liikumisest tingitud mürad, mis asuvad PPG-signaali sagedusdiapasoonis, ja määrata PPG-signaali tõusev front. 